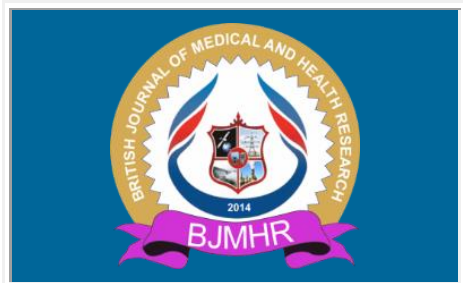

\title{
BJMHR
}

British Journal of Medical and Health Research Journal home page: www.bjmhr.com

\section{Metal-Ceramic Bond Strength of Substrates Made With Different Fabrication Techniques: In Vitro Study}

\section{Christina Mouchtaridi, DT ${ }^{1}$, Marta Muñoz Hernández, DCS, ${ }^{2}$ Konstantin Spyropoulos DDS, ${ }^{3}$ Triantafyllos Papadopoulos, DDS $^{1 *}$}

1.MSc in Dental Biomaterials, Department of Dental Biomaterials, School of Dentistry, National and Kapodistrian University, Thivon 2, Athens, Greece.

2. Department of Material Science and Engineering, University Rey Juan Carlos, C/Tulipán s/n, 28933 Móstoles, Madrid, Spain.

3. Department of Dental Technologies, Faculty of Health and Care, University of West Attica, Athens, Greece, Ag. Spyridonos 32, Athens, Greece.

4. Department of Dental Biomaterials, School of Dentistry, National and Kapodistrian University, Thivon 2, Athens, Greece.

\section{ABSTRACT}

The purpose of this in vitro study was to determine the metal-ceramic bond strength between dental porcelain and cobalt-chromium ( $\mathrm{Co}-\mathrm{Cr}$ ) metal substrates fabricated by different techniques. Forty Co-Cr metal substrates were fabricated according to ISO 9693-1, by casting, milling, soft milling, and DMLS. Forty additional substrates were fabricated for each technique to record the modulus of elasticity. A commercially available feldspathic porcelain was placed on the substrates, and then the specimens were also tested for metal-ceramic bond strength with the 3-point bend test, according to ISO 9693-1. The fractured specimens were observed with optical and scanning electron microscopy using electron dispersive spectroscopy to define the mode of failure. X-ray diffraction spectroscopy was conducted to determine changes in crystalline phases after fabrication and the 3-point bend test. Statistical analysis was with 1way analysis of variance and the Tukey post hoc test $(\alpha=.05)$. No statistically significant differences were found for modulus of elasticity among any of the groups. The metal-ceramic bond strength for casting had no statistically significant differences and the mode of failure in all groups was cohesive. The metallographic analysis of the as-received, the after porcelain firing, and the after 3-point bend test specimens revealed changes in microstructure. The crystallographic microstructure revealed that the patterns had minor changes among the groups. The study revealed that all of the techniques showed similar results. The modulus of elasticity and metal-ceramic bond strengths presented no statistically significant differences, and the mode of failure was cohesive.

Keywords. Metal-ceramic, Bond Strength, Casting, Milling, Soft Milling, DMLS, Laser Sintering.

*Corresponding Author Email: trpapad@ dent.uoa.gr

Received 10 June 2020, Accepted 24 June 2020

Please cite this article as: Mouchtaridi C et al., Metal-Ceramic Bond Strength of Substrates Made With Different Fabrication Techniques: In Vitro Study. British Journal of Medical and Health Research 2020. 


\section{INTRODUCTION}

Metal substrates for metal-ceramic restorations were traditionally constructed by casting dental alloys, but in recent years, new technologies have offered alternative solutions. The most common of these are the three-dimensional (3D) subtractive and additive techniques, such as milling and soft milling, which are methods that involve cutting the substrate from a soft material, followed by thermal treatment in an oven, and the direct metal laser sintering (DMLS) technique, which involves the construction of the metal substrates layer by layer with metal powder and a laser. Many researchers ${ }^{1-9}$ have published articles concerning experiments with these techniques, using mostly cobalt-chromium ( $\mathrm{Co}-\mathrm{Cr}$ ) alloys and testing different factors which influence the metal-ceramic bond strength. Also, many results have been published ${ }^{10-14}$ regarding bond strength values related to microstructural changes of alloys used under different processing and thermal conditions.

In addition, Co-Cr alloys have been utilized with these new technologies because they involve less concern about biocompatibility than the traditional cast nickel-chromium (Ni-Cr) alloys, for metal-ceramic prostheses. The purpose of the present research was to study the bond strength between $\mathrm{Co}-\mathrm{Cr}$ alloys and a feldspathic dental porcelain when casting, milling, soft milling, and DMLS techniques were used, according to ISO 9693-1, ${ }^{15}$ to construct the substrates. The null hypothesis of the present study was that there would be no statistically significant differences in the metal and ceramic bond strengths for any of the fabrication techniques used for the construction of the metal substrates.

\section{MATERIALS AND METHOD}

Forty metal substrates were fabricated by casting, milling, soft milling, or DMLS techniques according to ISO 9693-1 requirements. The metal substrates were classified into 4 equal groups of 10, as shown in Table 1. In addition, 40 metal substrates were fabricated, 10 with each technique, to test the modulus of elasticity (E) (Table 1). Twenty-one plastic patterns were fabricated using custom-made equipment ${ }^{16}$ to the exact dimensions specified by ISO 9693-1 (length $25 \pm 1 \mathrm{~mm}$, width $3 \pm 0.1 \mathrm{~mm}$, and thickness $0.5 \pm 0.05 \mathrm{~mm}$ ).

Twenty of the specimens were positioned in casting rings, with an investment material (Giroinvest Super; Amann Girrbach) and then cast using a Co-Cr alloy (Phase-C3; Unitech). The investment material was removed by sandblasting with $110-\mu \mathrm{m} \mathrm{Al}_{2} \mathrm{O}_{3}$ particles (Cobra; Renfert) with $200 \mathrm{kPa}$ pressure. The one plastic pattern left was used for the scanning procedure (Ceramill Map 400; Amann Girrbach) to create the digital prototype, and a standard tessellation language (STL) file was created for the milling, soft milling, and DMLS techniques.

The milling was performed with a YenaDentD40 5-axis cutting machine (YenaDent Europe), using a Co-Cr 10-mm Magnum Splendidum 4 disc (Mesa). 
The soft milling was performed with a Ceramill Motion 2 5-axis cutting machine (Amann Girrbach) using a 10-mm Co-Cr special soft disc Ceramill Sintron from the same company for the milling. After the soft milling procedure, all of the substrates of this group were subjected to thermal processing in a Ceramill Argotherm 2 furnace (Amann Girrbach) to acquire the optimum mechanical properties.

The DMLS substrates were created using the 3Shape program with the STL file, and then with an MLab cusing machine (Concept Laser) using the 10-30 $\mu \mathrm{m}$ Co-Cr powder Remanium Star CL (Dentaurum). The compositions of the manufacturers ' $\mathrm{Co}-\mathrm{Cr}$ alloys are presented in Table 2.

Ten substrates from each group were submitted to a 3-point bend test in a universal testing machine (Tensometer10; Monsanto). A standard load was applied with a crosshead speed of $1.5 \mathrm{~mm} / \mathrm{min}$ and a distance between the supporting points of $20 \mathrm{~mm}$. The E was calculated using the following formula: $\mathrm{E}=\mathrm{L} 3 \Delta \mathrm{P} / 4 \mathrm{bh} 3 \Delta \mathrm{d}$, where $\mathrm{L}$ is the distance between the supporting rods $(20 \mathrm{~mm}), \mathrm{b}$ is the width of the specimen $(3 \mathrm{~mm}), \mathrm{h}$ is the thickness of the specimen $(0.5$ $\mathrm{mm}), \Delta \mathrm{P}$ and $\Delta \mathrm{d}$ are the load and deflection increment, respectively, between the 2 specific points in the elastic portion of the curves.

The porcelain was applied in layers. The first layer was the bonding agent (Metablend; Unitech), the second and third layers were the opaque and dentin of Noritake EX-3 dental feldspathic porcelain (Kuraray; Noritake Dental). The ceramic materials were applied centrically on 1 side of the metal substrate using custom-made equipment adjusted to the dimensions specified in the ISO 9693-1 requirements (length $8 \pm 0.1 \mathrm{~mm}$, width $3 \pm 0.1 \mathrm{~mm}$, thickness $1.1 \pm 0.1 \mathrm{~mm}$ ). The specimens were fired at $980 \pm 5^{\circ} \mathrm{C}$ with the temperature increasing at rate of $80^{\circ} \mathrm{C} / \mathrm{min}$ in vacuum conditions in a Dekema Dental Keramik oven (Austromat 624). After the preparation of the metal-ceramic specimens, a 3-point bend test was performed with the same equipment (Tensometer10; Monsanto) that was used for the definition of E. The load was applied on the opposite side from the porcelain layers. Fracture diagrams were obtained, and the bonding strength was calculated using the following formula: $\sigma=3 \mathrm{FL} / 2 \mathrm{bd} 2$ where $\sigma$ is the tension, $F$ is the largest amount of weight that is applied $(\mathrm{N}), \mathrm{L}$ is the distance between the 2 supporting rods $(\mathrm{mm}), \mathrm{b}$ is the width of the specimen $(\mathrm{mm})$, and $\mathrm{d}$ is the thickness $(\mathrm{mm})$. An optical stereoscopic microscope (Eclipse ME 600; Nikon-Kogaku) was used to define the mode of failure of the fractured parts of the specimens of each group (Fig. 1) under reflected light, at $\times 5$ magnification. To verify the result of the present study, these areas were recorded to measure the percentage of the ceramic mass, for the next measurements regarding the modes of failure. 

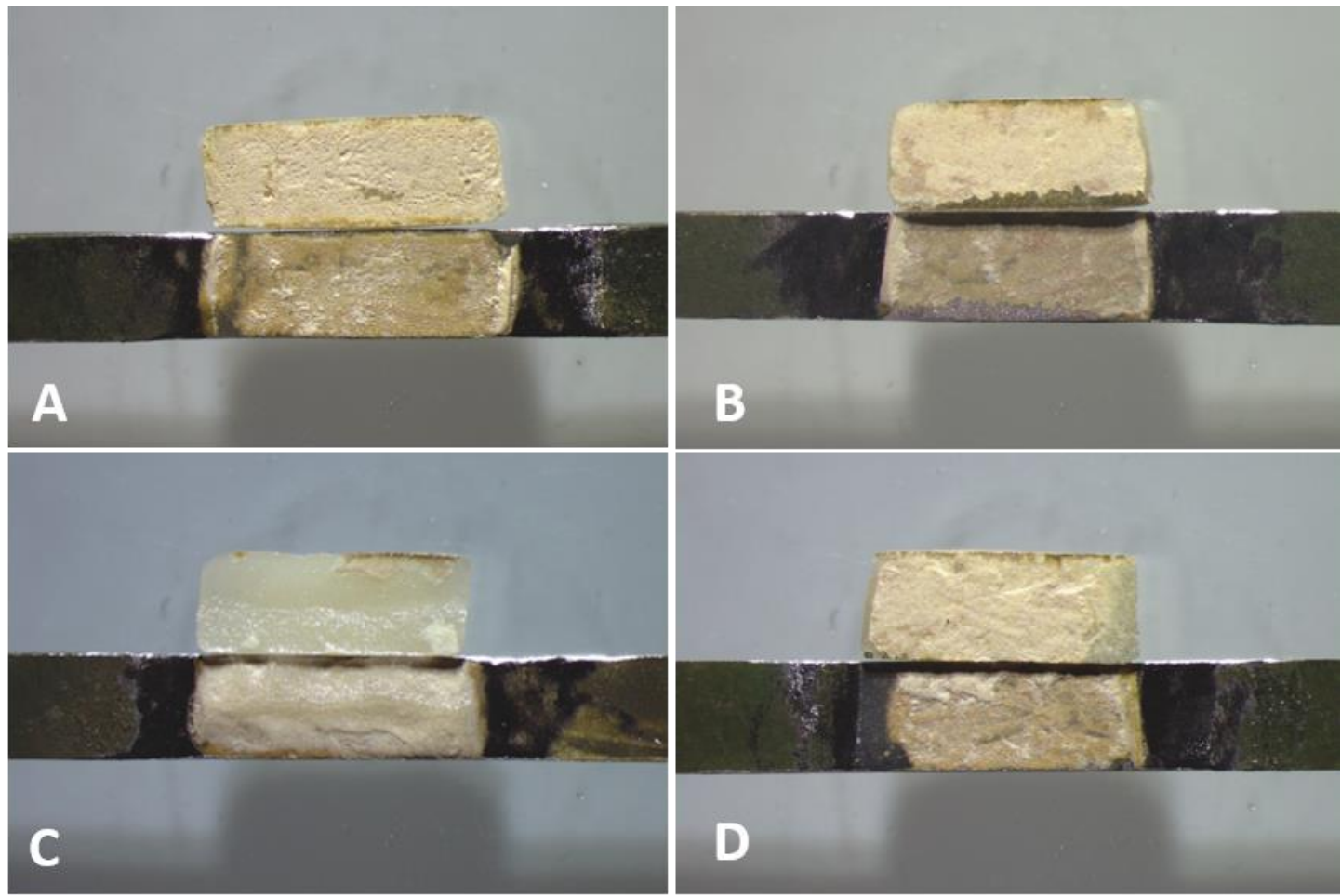

Figure 1: Metal-ceramic specimens after 3-point bend test (original magnification $\times 5$ ). A, Cast. B, Milled. C, Soft milled. D, direct metal laser sintered.

To verify the kind of material of the different colored areas recorded with optical microscopy, some selected areas of the fractured surfaces were observed in a scanning electron microscope (SEM; JEOL 6380LV) operating at an accelerating voltage of $30 \mathrm{kV}$, by secondary electron images at $\times 100$ magnification. The qualitative and quantitative definitions of the elemental distribution were obtained by X-ray energy dispersive spectroscopy (EDS) using a super ultrathin beryllium window (Sapphire; Edax Intl). The EDS area (mapping) analysis was obtained in representative metal substrates as received from the manufacturer, for each group, as well as the bonding agent and opaque porcelain before their use on the substrates. The EDS analysis was also conducted on specific areas of the fractured specimens.

Cohesive failure was defined as $>50 \%$ of the fractured surface of the specimen covered by ceramic material (including bonding agent), whereas adhesive failure was defined as $<50 \%$. The mode of failure in all of the groups in this study was cohesive.

Phase composition was analyzed by X-ray diffraction (XRD) using a Philips X'Pert diffractometer operating with $\mathrm{CuK} \alpha=1.54056 \AA$, scanning speed of $0.01^{\circ} / \mathrm{s}$ from $10^{\circ}$ to $90^{\circ}$, and scanning range of $2 \theta$, with metallographic preparation of the patterns to observe the grain size by microscopy. The peaks for the 4 techniques were identified by comparing every alloy processed, with standard files from International Centre for Diffraction Data (ICDD; documents 96-901-2928 for Co-fcc, 96-901-1618 for Co-hcp, and 96-231-0285 for intermetallic $\mathrm{Co}_{7} \mathrm{Cr}_{8}$ ). Additives were also identified by 01-076-0319 for $\mathrm{TiO}_{2}$ and 00-0040593 for $\mathrm{CeO}_{2}$. To compare the processing method for every Co-Cr alloy of the 4 groups used 
in the present study, XRD patterns were used and divided into groups of as-received, after porcelain firing, and after 3-point bend test patterns. The mean value and standard deviation were calculated for $\mathrm{E}$.

Bond strength was statistically analyzed by 1-way analysis of variance (ANOVA) and Tukey post hoc test; $P<.05$ was considered statistically significant.

\section{RESULTS AND DISCUSSION}

The results for $\mathrm{E}$ of the 4 different techniques applied for the fabrication of the metal substrates are presented in Table 3. No statistically significant difference was recorded among the tested groups $(P=0.268)$. The results for metal-ceramic bond strength are presented in Table 4. Again, no statistically significant difference was recorded among the tested groups $(P<0.173)$. The results of the EDS area analysis of the as-received ceramic materials (bonding agent, porcelain) revealed that the bonding agent presented an increased amount of $\mathrm{Ti}$, while $\mathrm{Zr}$ and $\mathrm{Si}$ were the main elements detected in the opaque porcelain. The mode of failure for all groups was cohesive.

Also, XRD analysis of the used alloys was conducted. The 2 typical primary phases of the casting group of Co-Cr alloys, $\gamma$-fcc $(\gamma-\mathrm{Co}-\mathrm{Cr}$-fcc) and $\varepsilon$-hcp ( $\varepsilon$-Co-Cr-hcp), were found in the as-received alloys. Also another phase that fit with intermetallic $\mathrm{Co}_{7} \mathrm{Cr}_{8}$ was revealed. After porcelain firing and after the 3-point bend test, the Co-Cr-fcc became the major phase. In addition, $\mathrm{TiO}_{2}$ and $\mathrm{CeO}_{2}$ were identified showing that the presence of porcelain and of $\mathrm{Co}-\mathrm{Cr}$ hcp could not be discounted, because their peaks appeared in the same place as those of the additives from opaque porcelain. The amorphous halo observed at low angles (below 25 degrees) in the after porcelain firing group and after the 3-point bend test, was the result of their additive content. As in the casting specimens, the patterns of the as-received milling group showed the $2 \mathrm{fcc} / \mathrm{hcp} \mathrm{Co}-\mathrm{Cr}$ phases together with an intermetallic $\mathrm{Co}_{7} \mathrm{Cr}_{8}$ phase. In APFA3PBT patterns, the Co-Cr-fcc became the major phase, in combination with the $\mathrm{TiO}_{2}$ and $\mathrm{CeO}_{2}$ phases. The amount of intermetallic phase decreased. The results recorded for the $\mathrm{Co}-\mathrm{Cr}$ alloys from the soft milling technique revealed that the major phase was Co-Cr-hcp, whereas the $\mathrm{Co}-\mathrm{Cr}$-fcc phase was practically undetectable. Intermetallic $\mathrm{Co}_{7} \mathrm{Cr}_{8}$ peaks were also identified. In the patterns for the after porcelain firing group and the 3-point bend test, only the presence of Co-Cr-hcp phase was recorded, while no intermetallic peaks were detected. The DMLS patterns for as-received specimens showed the same phases as the casting and milling specimens. In the patterns for after porcelain firing and the 3-point bend test, the intermetallic peaks disappear, and the presence of $\mathrm{Co}-\mathrm{Cr}-\mathrm{fcc}$ phase becomes much more evident. The components $\mathrm{TiO}_{2}$ and $\mathrm{CeO}_{2}$ were clearly detected, as in the patterns referred to previously in the after porcelain firing group and the 3-point bend test. 
Table 1: Study groups

\begin{tabular}{lll}
\hline Groups & $\begin{array}{l}\text { Substrates for Testing } \\
\text { Metal-Ceramic Bond } \\
\text { Strength (n) }\end{array}$ & $\begin{array}{l}\text { Substrates for Testing } \\
\text { Modulus of Elasticity of } \\
\text { Alloys (n) }\end{array}$ \\
\hline Cast & 10 & 10 \\
Milled & 10 & 10 \\
Soft milled & 10 & 10 \\
DMLS* & 10 & 10 \\
\hline
\end{tabular}

*DMLS, direct metal laser sintered.

Table 2: Compositions of the alloys used provided by the manufacturers

\begin{tabular}{|c|c|c|c|}
\hline $\begin{array}{l}\text { Co-Cr Alloys and } \\
\text { Manufacturers }\end{array}$ & Composition (wt \%) & $\begin{array}{l}\text { Lot/Patch } \\
\text { Number }\end{array}$ & $\begin{array}{l}\text { Country of } \\
\text { Origin }\end{array}$ \\
\hline Phase-C3, Unitech & $\begin{array}{l}\mathrm{Cr}, 28 \% ; \mathrm{W}, 8.5 \% ; \mathrm{Si}, 1.5 \% ; \mathrm{Nb}, \\
1 \% ; \mathrm{Co}, 60.5 \% ; \mathrm{C}, 0.02 \%\end{array}$ & PHC74 & France \\
\hline $\begin{array}{l}\text { Magnum Splendidum } \\
\text { Type 4, Mesa }\end{array}$ & $\begin{array}{l}\mathrm{Cr}, 28 \% ; \mathrm{W}, 9 \% ; \mathrm{Si}, 1.5 \% ; \mathrm{Nb}, \\
1 \% ; \mathrm{Co}, 60 \% ; \mathrm{Mn}, \mathrm{Fe}\end{array}$ & 1021210 & Italy \\
\hline $\begin{array}{l}\text { Ceramill Sintron, } \\
\text { Amann Girrbach }\end{array}$ & $\begin{array}{l}\mathrm{Cr}, 28 \% ; \mathrm{Mo}, 5 \% ; \mathrm{Co}, 66 \% ; \mathrm{Mn} \text {, } \\
\mathrm{Si}, \mathrm{Fe}\end{array}$ & $\begin{array}{l}1602011- \\
160\end{array}$ & Austria \\
\hline $\begin{array}{l}\text { Remanium Star CL, } \\
\text { Dentaurum }\end{array}$ & $\begin{array}{l}\mathrm{Cr}, 28 \% ; \mathrm{W}, 9 \% ; \mathrm{Si}, 1.5 \% ; \mathrm{Co} \\
60.5 \% ; \mathrm{Mn}, \mathrm{N}, \mathrm{Nb}, \mathrm{Fe}\end{array}$ & $463369 \mathrm{~A}$ & Germany \\
\hline
\end{tabular}

Table 3: Modulus of elasticity for the alloys tested ${ }^{\text {a }}$

\begin{tabular}{ll}
\hline Groups & E (GPa) \\
\hline Cast & $229.8 \pm 25.4$ \\
Milled & $216.8 \pm 21.9$ \\
Soft milled & $251.8 \pm 19.9$ \\
DMLS* & $228.3 \pm 20.1$ \\
\hline
\end{tabular}

*DMLS, direct metal laser sintered; E. modulus of elasticity. ${ }^{a}$ Values are means \pm standard deviation $(n=10)$.

Table 4. Metal-ceramic bond strengths ${ }^{\mathrm{a}}$

\begin{tabular}{ll}
\hline Groups & Bond Strength (MPa) \\
\hline Cast & $44.8 \pm 7.9$ \\
Milled & $48.4 \pm 4.5$ \\
Soft Milled & $44.1 \pm 9.4$ \\
DMLS* & $44.5 \pm 8.7$ \\
\hline
\end{tabular}

*DMLS, direct metal laser sintered. ${ }^{a}$ Values are means \pm standard deviation $(n=10)$.

\section{DISCUSSION}

According to the results of the present study, the null hypothesis was verified, and no statistically significant difference was found among the tested groups concerning the metalceramic bond strength. The results for modulus of elasticity of all tested $\mathrm{Co}-\mathrm{Cr}$ alloys were in accordance with the data provided by the companies and that reported in the literature. Regarding XRD, the pure solid cobalt was (under equilibrium conditions) face-centered cubic (fcc) above $419^{\circ} \mathrm{C}$ and hexagonal close-packed (hcp) below $419^{\circ} \mathrm{C} .{ }^{17}$ The pure solid $\mathrm{Cr}$ showed the body-centered cubic phase $(\mathrm{Cr}-\mathrm{bcc})$ as departure phase; however, the solid-state transformation of Co from fcc to hep was slow, so the $\mathrm{C}$-fcc phase was retained under normal 
conditions. Changes which were related to fcc or hcp Co-Cr could be explained by the use of mechanical or thermal treatments based on the departure phases. Reference works on dental materials ${ }^{18}$ refer to $\mathrm{E}$ values for $\mathrm{Co}-\mathrm{Cr}$ alloy in $\mathrm{MPa}$, and Dimitriadis et $\mathrm{al}^{4}$ found $\mathrm{E}$ values of 222 and $227 \mathrm{MPa}$ for Co-Cr alloys used in casting and DMLS methods, respectively. Most researchers ${ }^{1,2,4-9}$ who have studied metal-ceramic bond strength in vitro using casting and selective laser melting (SLM) techniques based on ISO 9693 have found fracture values between 37 and $47 \mathrm{MPa}$ for casting and 45 and $50 \mathrm{MPa}$ for DMLS, with no statistically significant differences. These results are consistent with the results of the present study (44.844.5 MPa), where also no statistically significant differences were recorded. Exceptions to these fracture values, including the high values recorded by Lawaf et $\mathrm{al}^{3}$ between cast $(74.94$ $\pm 16.06 \mathrm{MPa})$ and SLM $(69.02 \pm 5.77 \mathrm{MPa})$ groups, and low values recorded by Li et al ${ }^{1}$ (cast $32.15 \pm 2.39 \mathrm{MPa}$ and SLM $32.31 \pm 3.06 \mathrm{MPa}$ ), can attributed to the different procedures followed during the fabrication of the specimens.

Researchers who have studied metal-ceramic bond strength for metal substrates produced by milling ${ }^{1,2}$ have found fracture values between 34 and $43.3 \mathrm{MPa}$, which are slightly less than the results of the present study (48.4 MPa). Other researchers followed different fracture testing procedures to record metal-ceramic bond strength using ANSI/ADA No. 388 and shear tests. ${ }^{9,19}$ They found no significant difference in bond strength between cast and selective laser sintering (SLS) techniques. In particular, Lee et al $^{19}$ studied metal-ceramic shear bond strength in specimens produced by soft milling, and found a value of $35.1 \mathrm{MPa}$, which was close to the value recorded in the present study (44.1 MPa).

Most of the previously mentioned studies were accompanied by testing for mode of failure. The results revealed cohesive fractures in the majority of the tests, independent of the fracture method used. ${ }^{1-5}$ Many researchers report mixed adhesive and cohesive failure, with cohesive failure the more prevalent. ${ }^{4,5,9,19}$

Al Jabbari et al ${ }^{10}$ compared the metallurgical microstructures of $\mathrm{Co}-\mathrm{Cr}$ dental alloys fabricated via casting, milling, and SLM. Different microstructures were identified among the groups. Their study also focused on the interfacial characterization of $\mathrm{Co}-\mathrm{Cr}$ porcelain fused to metal (PFM) alloys fabricated using casting, milling, and SLS. Kim et $\mathrm{al}^{12}$ evaluated the microstructure and mechanical properties of Co-Cr dental alloys fabricated by 3 computeraided design and computer-aided manufacturing (CAD-CAM) techniques and compared them with the traditional casting technique. They found that the microstructure of the alloys was strongly influenced by the manufacturing processes, and the SLM group showed superior mechanical properties. Several studies have been conducted regarding the DMLS technique: $\mathrm{Wu}$ et $\mathrm{al}^{7}$ studied the microstructure of Co-Cr dental alloy using the SLM technique for the specimens, and compared it with casting. The microstructure of the SLM group appeared to be 
oriented, which gives good mechanical properties. The results of elemental analysis using SEM/EDS revealed that SLM showed slightly better bond strength due to the intermediate layer between the metal substrate and the porcelain. Barucca et $\mathrm{al}^{11}$ used Co-Cr-Mo specimens produced by DMLS for hardness and structural characterization compared with cast ones and analyzed by XRD, SEM, transmission electron microscopy, and energy-dispersive X-ray spectroscopy, revealing that the face-centered cubic phase of the sintered alloy showed increased hardness.

A study by Koutsoukis et $\mathrm{al}^{13}$ showed the advantages of using the SLM technique for substrate fabrication in dental structures, in comparison with casting and milling techniques. Li et al, ${ }^{14}$ in an experimental study, produced Co-Cr specimens by casting, powder metallurgy, and CADCAM, and analyzed those using EBSD EDS and XRD. Specimens were treated using different porcelain firings, and crystallography, grain size, and chemical composition were analyzed. Krug et $\mathrm{al}^{18}$ did a comparison of 3 different forces on metal-ceramic systems fabricated using 3 different techniques. Specimens were subjected to thermal and mechanical aging. The only statistically significant difference was recorded in force maximum for specimens without thermal and mechanical aging. Thermal versus mechanical aging did not significantly affect the result. Serra-Prat et $\mathrm{al}^{20}$ conducted shear bond strength tests to determine the metal-ceramic bond strengths for milling, casting, and laser sintering (LS) techniques, after thermocycling procedure, and analyzed the results using 2-way ANOVA. They found that there were no statistically significant differences among the 3 techniques, between either the thermocycled or nonthermocycled specimens of the LS group, in contrast to the cast and milled groups where they observed adhesion differences. Suleiman et $\mathrm{al}^{21}$ made identical crowns with milled, cast, and LS alloy using a Co-Cr and high gold alloy. There were no statistically significant differences among the 3 groups for fracture strength, whereas high gold alloy crowns revealed statistically significantly higher metal-ceramic bond strength. Tuna et $\mathrm{al}^{22}$ conducted an electrochemical corrosion experiment for metal substrates produced by milling, casting, or LS using a Co-Cr alloy, and found that the corrosion resistance was greater in the LS group than in the cast group. Kruth et $\mathrm{al}^{23}$ compared the mechanisms of the SLS and SLM techniques, which can be classified into the categories of solid state sintering, chemically induced binding, and liquid phase sintering. In this paper, they describe all of the possible results that can be achieved by these techniques, including metal constructions as well. Also, as it can be observed in tables 3 and 4 , the sources of variation given for the individual specimen measurements for the elastic modulus and metal-ceramic bond strength are close enough to the results given at the similar studies.

This present study had some limitations, including the poor resolution of the SEM images and XRD graphics that were therefore difficult to provide to accompany the text. As a suggestion 
for future research, it would be useful to analyze the longevity of each of these constructions, comparing the groups. Also, another possible study could include these 4 groups to reveal the best effect on tissues, and which one would be more suitable. Furthermore, it would be interesting to analyze the ions released from these materials. Given all of the new technologies that are now a part of the production of fixed dental prostheses and looking forward to new technologies that may emerge, a similar study including also 3D printers might give valuable insights.

\section{CONCLUSION}

Within the limitations of the present laboratory study, the following conclusions can be drawn: The modulus of elasticity of Co-Cr dental alloys fabricated by casting, milling, soft milling, or DMLS is similar for all fabrication methods. Metal-ceramic bond strength is satisfactory in all cases, covering the minimum acceptable value of the $25 \mathrm{MPa}$ suggested by ISO 9693-1. The mode of failure can be expected to be cohesive, independent of the fabrication method of the metallic substrate. XRD analysis reveals differences in microstructure between the as-received metallic substrates and the fractured specimens within each group. $\mathrm{Co}-\mathrm{Cr}-\mathrm{fcc}$ is the major phase in the as-received alloys for casting, milling, and DMLS techniques. An increase in the formation of Co-Cr-fcc phase is observed after the porcelain firing cycle and the 3-point bend test for the casting, milling, and DMLS methods. The Co-Cr-fcc structure is not maintained with the soft milling technique, while Co-hcp is the dominant phase in the soft milling alloy before and after porcelain firing and the 3-point bend test. An intermetallic compound, $\mathrm{Co}_{7} \mathrm{Cr}_{8}$, is formed in all of the as-received alloys. The presence of this intermetallic compound drastically decreases after porcelain firing and the 3-point bend test for cast and milled alloys, and completely disappears with the soft milling and DMLS techniques.

\section{ACKNOWLEDGMENTS}

Special thanks to Mr A. Chatzipmatzakis for his contribution in the fabrication of the metal ceramic specimens. Also many thanks for the contribution in SEM analysis to Mr P. Tsakiridis and Mrs E. Gomoza

\section{REFERENCES}

1. Li J, Chen C, Liao J, et al. Bond strengths of porcelain to cobalt-chromium alloys made by casting, milling, and selective laser melting. J Prosthet Dent 2017;118:69-75.

2. Wang H, Feng Q, Li N, et al. Evaluation of metal-ceramic bond characteristics of three dental Co-Cr alloys prepared with different fabrication techniques. J Prosthet Dent 2016;116:916-23.

3. Lawaf S, Nasermostofi S, Afradeh M, et al. Comparison of the bond strength of ceramics to $\mathrm{Co}-\mathrm{Cr}$ alloys made by casting and selective laser melting. J Adv 
Prosthodont 2017;9:52-6.

4. Dimitriadis K, Spyropoulos K, Papadopoulos T. Metal-ceramic bond strength between a feldspathic porcelain and Co-Cr alloy fabricated with Direct Metal Laser Sintering technique. J Adv Prosthodont 2018;10:25-31.

5. Xiang N, Xin XZ, Chen J, et al. Metal-ceramic bond strength of Co-Cr alloy fabricated by selective laser melting. J Dent 2012;40:453-57.

6. Bae EJ, Kim JH, Kim WC, et al. Bond and fracture strength of metal-ceramic restorations formed by selective laser sintering. J Adv Prosthodont 2014;6:266-71.

7. Wu L, Zhu H, Gai X, et al. Evaluation of the mechanical properties and porcelain bond strength of cobalt-chromium dental alloy fabricated by selective laser melting. J Prosthet Dent 2014;111:51-5.

8. Kul E, Aladag LI, Duymus ZY. Comparison of the metal-ceramic bond after recasting and after laser sintering. J Prosthet Dent 2015;114:109-13.

9. Akova T, Ucar Y, Tukay A, Balkaya MC, Brantley WA. Comparison of the bond strength of laser-sintered and cast base metal dental alloys to porcelain. Dent Mater 2008;24:1400-4.

10. Al Jabbari YS, Koutsoukis T, Barmpagadaki X, et al. Metallurgical and interfacial characterization of PFM Co-Cr dental alloys fabricated via casting, milling or selective laser melting. Dent Mater 2014;30:79-88.

11. Barucca G, Santecchia E, Majni G, et al. Structural characterization of biomedical CoCr-Mo components produced by direct metal laser sintering. Mat Sci Eng C 2015;48:263-9.

12. Kim HR, Jang S-H, Kim YK, et al. Properties of Co-Cr dental alloys fabricated by three CAD/CAM-based processing techniques. Materials 2016;9:596. doi:10.3390/ma9070596.

13. Koutsoukis T, Zinelis S, Eliades G, et al. Selective laser melting technique of Co-Cr dental alloys: a review of structure and properties and comparative analysis with other available techniques. J Prosthodont 2015;24:303-12.

14. Li KC, Prior DJ, Waddell JN, et al. Comparison of the microstructure and phase stability of as-cast, $\mathrm{CAD} / \mathrm{CAM}$ and powder metallurgy manufactured Co-Cr dental alloys. Dent Mater 2015;31:306-15.

15. International Organization for Standardization. ISO 9693-1: Dentistry-compatibility testing. Metal-ceramic systems. Geneva, Switzerland, 2012.

16. Spyropoulos K, Dimitriadis K, Karouzos K, et al. Original dimensional instruments for metal-ceramic specimens according to ISO 9693. Odontostomat Prog 2017;71:94-105.

17. Ratner B, Hoffman A, Schoen F, et al. Biomaterials science: An introduction to 
materials in medicine. Philadelphia, PA: Academic Press; 2012.

18. Krug KP, Knauber AW, Nothdurft FP. Fracture behavior of metal-ceramic fixed dental prostheses with frameworks from cast or a newly developed sintered cobalt-chromium alloy. Clin Oral Investing 2015;19:401-11.

19. Lee DH, Lee BJ, Kim SH, et al. Shear bond strength of porcelain to a new millable alloy and a conventional castable alloy. J Prosthet Dent 2015;113:329-35.

20. Serra-Prat J, Cano-Batalla J, Cabratosa-Termes J, et al. Adhesion of dental porcelain to cast, milled, and laser-sintered cobalt-chromium alloys: shear bond strength and sensitivity to thermocycling. J Prosthet Dent 2014;112:600-5.

21. Suleiman SH, Vult von Steyern P. Fracture strength of porcelain fused to metal crowns made of cast, milled or laser-sintered cobalt-chromium. Acta Odontol Scand 2013;71:1280-9.

22. Tuna SH, Özçiçek Pekmez N, Kürkçüoğlu I. Corrosion resistance assessment of Co-Cr alloy frameworks fabricated by $\mathrm{CAD} / \mathrm{CAM}$ milling, laser sintering, and casting methods. J Prosthet Dent 2015;114:725-34.

23. Kruth JP, Mercelis P, Froyen L, et al. Binding mechanisms in selective laser sintering and selective laser melting. Rapid Prototyping J 2005;11:26-36.

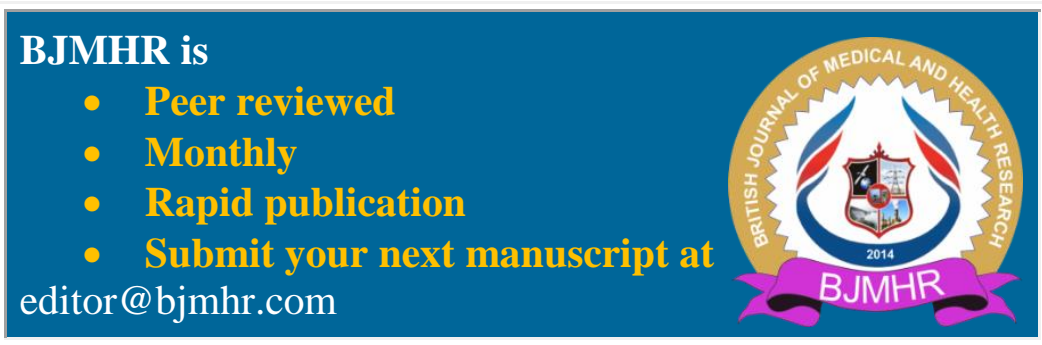

